\title{
AN UNUSUAL CASE OF SUBCUTANEOUS FAT NECROSIS IN A NEWLY BORN INFANT
}

\author{
BY \\ W. S. CRAIG \\ From the Department of Paediatrics and Child Health, University of Leeds
}

(RECEIVED FOR PUBLICATION SEPTEMBER 29, 1964)

Sclerema, scleroderma, and scleroedema are terms used to describe various conditions in the newly born with swelling and induration of areas of skin and the underlying subcutaneous tissues. Confusion, described by Macgregor (1960) as 'chaotic', has arisen from a loose use of the terms. McIntosh, Waugh, and Ross (1938) explain the historical origins of the confusion and mention the tendency for the term 'sclerema neonatorum' to be replaced by 'subcutaneous fat necrosis'. Credit for first describing this condition is usually accorded to Cruse $(1875,1879)$, but McIntosh and his co-workers consider that Usenbenzius (1722) was responsible for the first description.

In the newly born baby described below, bilateral axillary swellings were unexpectedly shown by biopsy examination to be the sites of fat necrosis.

\section{Case Report}

Obstetrical History. The infant was a male and the fourth child of a mother aged 38 years. There was no history of miscarriages, and the three older children are alive and well. The mother suffered from severe toxaemia, and labour was induced by artificial rupture of the membranes at the 39 th week. There was no history of maternal diabetes mellitus or of familial fat necrosis. Presentation was by the vertex. Irregularity of the foetal heart was noted before the onset of labour. Pethidine was administered three hours before delivery which was spontaneous.

The Baby at Birth. Weight 9 lb. 4 oz. $(4,195$ g.): length 24 in. $(61 \mathrm{~cm}$.).

The infant was asphyxiated. Respirations commenced four minutes after delivery and were persistently irregular, shallow, and accompanied by intercostal inspiratory indrawing for $\mathbf{3 6}$ hours. Traumatic cyanosis of the face and generalized hypotonicity were features, and the baby was semicomatose for $\mathbf{2 4}$ hours. Resuscitative measures included extraction of mucus, oxygen by mask, and the intramuscular administration of nalorphine $(0.4 \mathrm{mg}$.). A large quantity of foul-smelling blood-stained mucus was aspirated from the stomach.
Subsequent Clinical Course. The infant was nursed in an incubator from the time of birth. Initial difficulty was experienced in controlling body temperature which rose to $100^{\circ} \mathrm{F}$. $\left(37 \cdot 8^{\circ} \mathrm{C}\right.$.) on the third day and thereafter fluctuated between $100^{\circ} \mathrm{F}$. $\left(37 \cdot 8^{\circ} \mathrm{C}\right.$. $)$ and $99^{\circ} \mathrm{F} .\left(37 \cdot 2^{\circ} \mathrm{C}\right.$. $)$ for over two weeks. During the first 36 hours the cry was shrill though weak. On the second and third days of life large amounts of red urine were passed, containing massive quantities of urates and uric acid crystals but no red blood cells. The liver was enlarged and the spleen palpable but of normal size and consistence. Occasional regurgitation began on the third day and later acquired the character of moderately forceful vomiting which occurred irregularly once or twice daily for a fortnight. The general condition remained precarious until the fourth day, by which time the infant had lost $12 \mathrm{oz}$. $(340$ g.) in weight. Thereafter the weight trend was reversed and progressed uninterruptedly, the baby being discharged home at the age of 5 weeks.

The Axillary Swellings (Fig. 1). On the 13th day of life painless swellings in both axillae were noted for the first time. At first the swellings lacked precise definition and were of uncertain consistence. There was no crepitus to suggest surgical emphysema. On pressure the swellings disappeared into the depths of the axillae, and within 72 hours had grown sufficiently in size to be obvious to the naked eye. With continued increase in size they protruded from the axillae when the baby cried, but had neither the consistence nor definition of glands. Extremely mobile and without attachment to either the skin or underlying hard structures, the swellings felt fleshy on palpation, though the fleshy mass had embedded in it a curious ribbon-like meshwork of firmer consistence. There was no suggestion of matting, induration, or nodularity. Some five days after they were first noticed the swellings became more clearly defined and their mobility lessened. It was estimated that the mass in each axilla was 0.5 in. $(1.2 \mathrm{~cm}$.) in depth and had a maximum surface breadth of 1.5 in. $(3.5 \mathrm{~cm}$.). At no time was there any discoloration of the skin over the affected areas. A portion of the swollen tissues in the left axilla was taken on the 29th day of life for biopsy examination.

At the age of 2 months the axillary swellings were less obvious and by the age of 12 weeks had diminished greatly 


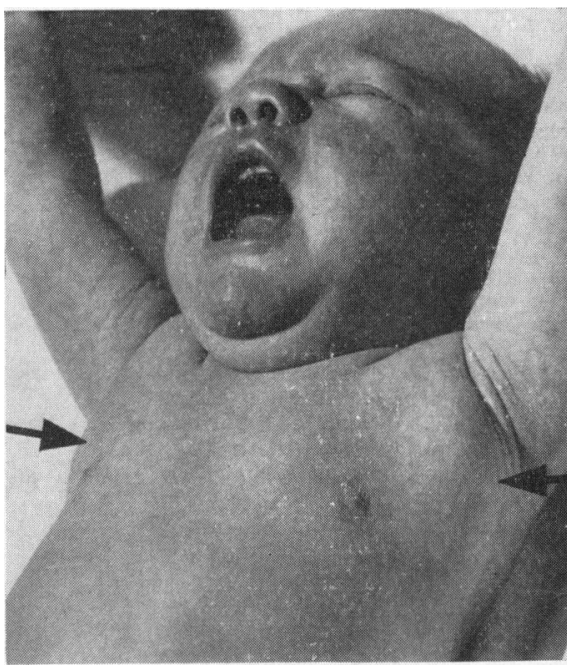

FIG. 1.-Swellings in the axillae on the 18th day of life.

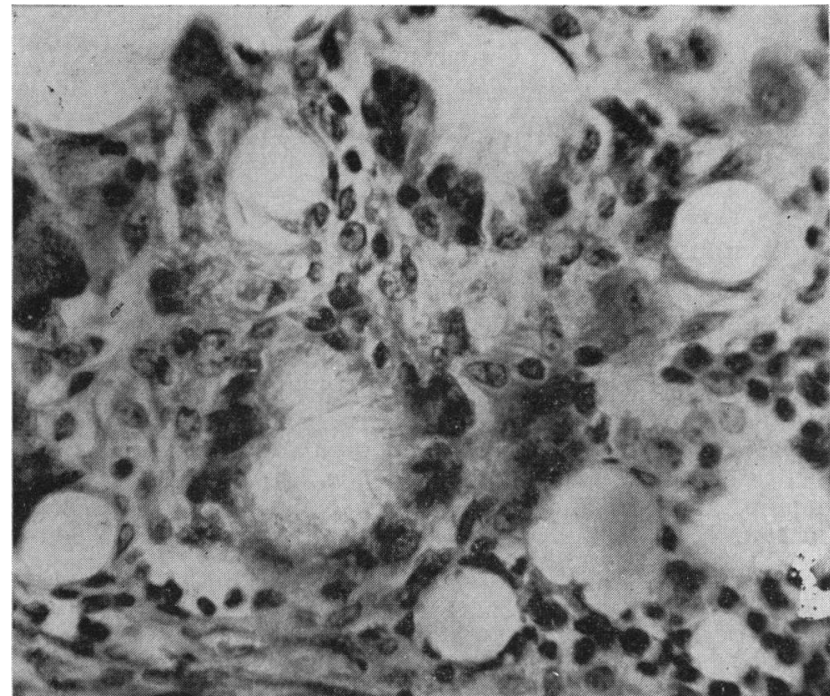

FIG. 2.-Multinucleate giant cells, containing sheaves of spaces representing crystals, in the granulation tissue. (H. and E. $\times 390$.) in size. Spontaneous disappearance was complete by the 4th month of life. Healing at the site of the biopsy scar was normal. There had been no recurrence of swellings when the child was re-examined at 2 years and again at 5 years of age.

Miscellaneous Investigations. Chest radiographs showed soft tissue swellings in the axillae but no evidence of calcium deposits. Lung fields were clear and there was no enlargement of mediastinal lymph nodes or of the thymus. Blood (at 15 days of age): WBC 10,000; polymorphs $22 \%$, lymphocytes $75 \%$, monocytes $2 \%$, myelocytes $1 \%$. No abnormal leucocytes or erythroblasts. Culture, sterile. Blood urea (at 15 days of age), serum calcium (at 18 days and 2 months), and serum potassium and sodium (at 18 days) all normal. Wassermann reaction negative; Mantoux test negative $(1 / 1,000)$ (at 2 months).

Micro-pathology (Dr. T. W. Sutherland). 'Lobulated adipose tissue, comprising most of the specimen, showed areas of necrosis sometimes associated with a pronounced but patchy granulomatous reaction.

'In some areas sheets of necrotic adipose-tissue cells were associated with little or no granulomatous reaction. Here the altered cells showed faintly eosinophilic, blurred cell-outlines, nuclear karyolysis, and calcification.

'In other parts a granulomatous reaction was associated with accumulations of foamy, sometimes multinucleate macrophages, as well as infiltrations of eosinophil polymorphs and lymphoid cells. Prominent giant cells were associated with fan-like arrangements of slender spaces-representing spicular crystals (Fig. 2).

'There was no evidence of recent haemorrhage, and no evidence of haemosiderin deposition, so that old haemor- rhage was unlikely. Vessels appeared normal. A little normal-looking lymphoid tissue was also present.'

\section{Discussion}

Biopsy examination established the diagnosis which was not suspected clinically. Possibilities were considered with dermatological and surgical colleagues, and diagnoses tentatively suggested, only to be discarded, included surgical emphysema, lymphangioma, reticulosis, and neurofibromatosis. The fact that fat necrosis was not seriously considered is explained by the absence of attachment of the skin to the underlying lesions (Fox, 1933; Papadia and Fransvea, 1958; Hering and Undeutsch, 1956), and of discoloration of the skin in the neighbourhood of the lesions (Papadia and Fransvea, 1958; Hering and Undeutsch, 1956). The sites of the lesions differed from those most commonly involved (Papadia and Fransvea, 1958; Hering and Undeutsch, 1956; Wesener, 1957; Fox, 1933). There was no local tenderness or plaque-like induration (Papadia and Fransvea, 1958; Fox, 1933; Wesener, 1957).

By way of contrast the case resembled others previously recorded in the onset of abnormal signs within three weeks of life (Papadia and Fransvea, 1958; Fox, 1933; Hering and Undeutsch, 1956; McIntosh et al., 1938), followed by disappearance within a few months (Papadia and Fransvea, 1958; Hering and Undeutsch, 1956; Wesener, 1957); birth at or after term with an average or above average birth weight (Papadia and Fransvea, 1958; Fox, 
1933); normal haematological and biochemical findings (Papadia and Fransvea, 1958; Hering and Undeutsch, 1956); and a tendency for the necrotic lesions to be distributed symmetrically (Fox, 1933).

\section{Summary}

An unusual case of subcutaneous fat necrosis appearing on the 13th day of life and disappearing spontaneously by the age of 4 months is described.

I am indebted to Dr. T. W. Sutherland for the pathological reports; to Mr. G. R. Pendrill, Librarian, Royal College of Physicians, Edinburgh for help with foreign literature; and to Dr. W. Goldie, Professor J. T. Ingram, and Mr. J. M. P. Clark, F.R.C.S., for their interest.

\section{REFERENCES}

Cruse, P. (1875). Ein Fall von Sclerodermie (sogenannt sclerodermia adultorum) bei einem Säugling. St. Petersb. med. Ztschr., 5, 306. (Quoted by Hering and Undeutsch, 1956.)

- (1879). Ueber sclerodermie bei neugeborenen sauglingen. Jb. Kinderheilk., 13, 35.

Fox, H. (1933). Subcutaneous fat necrosis of the new-born. Arch. Derm. Syph. (Chic.), 27, 237.

Hering, H., and Undeutsch, W. (1956). Zur Klinik und Pathogenase der adiponecrosis subcutanea neonatorum. Derm. Wschr., 134, 917.

Macgregor, A. R. (1960). Pathology of Infancy and Childhood, p. 579. E. \& S. Livingstone, Edinburgh and London.

McIntosh, J. F., Waugh, T. R., and Ross, S. G. (1938). Sclerema neonatorum (subcutaneous fat necrosis). Amer. J. Dis. Child., $55,112$.

Papadia, J., and Fransvea, P. (1958). Adiponecrosi del sottocutaneo del neonato. Minerva pediat., 10, 238.

Usenbenzius, J. A. (1722). Partus octimestris vivus, frigidus et rigidus. Acad. nat. curios. ephem., 9, 62.

Wesener, G. (1957). Zur Klinik und Therapie der Adiponecrosis subcutanea neonatorum. Arch. klin. exp. Derm. 206, 531. 